\title{
Real-time transit tracking system to evolve and facilitate the transportation process at the Applied Science University
}

\author{
Mohammad Shkoukani ${ }^{1 *}$, Fadi Ajjam², Hamza Ali ${ }^{2}$ and Hisham $\mathrm{Salah}^{3}$ \\ Associate Professor, Computer Science, Applied Science University, Kingdom of Bahrain ${ }^{1}$ \\ B.Sc. Student, Computer Science, Applied Science University, Kingdom of Bahrain ${ }^{2}$ \\ B.Sc. Student, Software Engineering, Applied Science University, Kingdom of Bahrain ${ }^{3}$
}

Received: 15-October-2015; Revised: 11-November-2015; Accepted: 02-December-2015

(C)2016 ACCENTS

\begin{abstract}
Travel and transportation are important for most people and play a major role in the human life; therefore this paper describes a prototype system called eBus which is a tracking system for campus buses at the Applied Science University. This system consists of two parts an Android application that is used by both the driver and the student which provides the ability for the students to track the buses' movements on a specific route and show their information on the map and it also enables the bus driver to see the students' locations on the map. The second part of the system is a windows application that is used by the transportation manager, the application allows the transportation manager to control \& monitor the transportation system, enables him to monitor the buses' movements, modify users, and notify him about the bus status. So, the main objective of our developed system is to facilitate the way of interactivity among the three actors (transportation manager, student, and bus driver) which make the transportation system convenient to use, more effective and efficient.
\end{abstract}

\section{Keywords}

Transportation, Tracking system, Global positioning system.

\section{Introduction}

Many people rely on public transportation, which provides them with movement and mobility from one place to another, transportation appears as an important mean to the students to travel from and to school and university [1]. Some of the most important desired features, among transit riders are real-time transit tracking and arrival time prediction [2]. The idea of our research became to our mind during our involvement in the current transportation system of the Applied Science University, which has three actors (Student, bus driver, and transportation manager). We have perceived that the mechanism of the transit process as the following: the transportation manager specifies the bus's paths, drivers and the bus's movement schedule, after that the driver starts his trip on a specific path, and students will be waiting on random locations on the path for bus arrival, when the bus reaches the student's location, the students will interact with the bus driver via hand signals in order to get on the bus.

\footnotetext{
*Author for correspondence
}

So the transit process runs as manual approach which is complex, not organized, and time consuming for all actors. Many problems have appeared such as transportation manager cannot monitor the bus movements efficiently and effectively, the bus drivers don't know the locations of the students on the path and the students don't know the exact time that the bus will reach them and they don't know if the bus has left them or not. Therefore, we have developed an android application and a Windows application instead of the manual system to solve those problems. The developed system allows the transportation manager to assign drivers to paths, drawing the paths on the map and enables him to monitor the buses' movements using the windows application that facilitates his work through enhancing the organization of the transportation process. The driver can know his path easily and clearly on the map using a hardware device (Tablet) as well as allowing the driver to see the students' locations on the path after student logging in and check-in. Finally the students can see the buses' movements and locations on a desired path, facilitate the interactivity between them and bus's drivers, provide the ability for the students to know the bus arrival time, which reduces 
student waiting time, and allowing the students to know if the bus left them or not.

\section{Related work}

Since transportation is very important to many people, therefore many transit systems and applications have appeared such as: ransitGenie which is a transit system that combine real time transit with transit schedule [3]. The cooperative transit tracking system is another system used in transit agencies to improve tracking services for the riders [4]. Gettaxi application (ComCab London) is a free portable software application which allows you to order a taxi from your mobile. It will pinpoint you on the map or use the location finder to pick from popular landmark around you, and showing you all available taxies in the area by using smart radar. Once your ride is confirmed, you will be able to see your cab on its way to you in real time. The application allows you to pay, tip your driver, and receipts will go directly to your email. You can also rate your driver, view previous journeys and earn taxi miles towards free rides [5]. Indiana University Bloomington-campus bus is a web based application provides basic transportation on campus for the Indiana university community and Bloomington residents. The system operates as a fixed- routes, scheduled service which is based on class times. This service is scheduled to have the maximum number of buses on campus during class times; it also provides bus schedules, live bus locations, and ridership statistics [6]. The University of Texas at Austin has an E-bus system for its students and employees, the system consists of three categories which are: events and alerts, Parking, Shuttles and commuting. The main category is Shuttles and commuting, which includes the routes, service calendar, E-Bus, and capital metro. The student can select the desired route with its schedule from the routes category. E-bus category is a late night service for students, staff, and faculty that picks up them from the University of Texas with drop off at Colorado. The students, staff, and faculty ride the E-bus free with no charge. So this university facilitates the transportation for its students and employees by using E-bus system [7]. New York University also provides its students with a real time map which shows the routes and schedules in the real time. So the students can see the buses' locations on the selected route [8].

\section{Research importance}

The importance of our work and especially our developed system is to overcome the weakness points of the actual transportation system in our university, facilitate the transportation process for the students, staff, and faculty who ride the university buses, and simplify the transportation management and monitoring for the transportation manager, So we developed a transportation system for our university similar to the systems that are used in the American universities with some additional features and capabilities as described in our system implementation to encourage our students to use universities buses in a smoothly way without any problems.

\section{System analysis and design}

The major functional requirements of the system to the three actors (students, driver, and transportation manager) as follows:

Student functional requirements: The system is able to locate the student location after the student pinpoint (check-in) on a specific path, the system allows the student to select a route, the system allows the student to select a bus on a selected route, the system presents the bus's movement-time to the students, the system shows the student bus's location on a specific path, and the system allows the student to checkout (unpin point) on a specific path.

Driver functional requirements: The system is able to locate the bus location after the driver login and start trip, the system shows the student's location to the driver, the system enables the driver to state the bus status as out of service, the system allows the driver to set the bus status as full so the system will notify the transportation manager that the bus is full, the system provides a route for the driver according to trips schedule, the system allows the driver to start the trip only when there is a route for him, and the system allows the driver to end the trip.

Transportation manager functional requirements: The system shows the transportation manger a list of buses and their status (bus is full or not), the system allows the transportation manager to pick a bus from the list and track it, and the system allows the transportation manager to modify the students and drivers information.

\subsection{System use-case diagram}

Figure 1 describes the interactions between the student and the system, it shows the main functions that the system provided to the student, firstly the student should log in to the system after that he can select a desired route, then check-in on a specific bus, so the system locates and displays the student on the 
map, Also the student can check out the selected bus, display buses departure time.

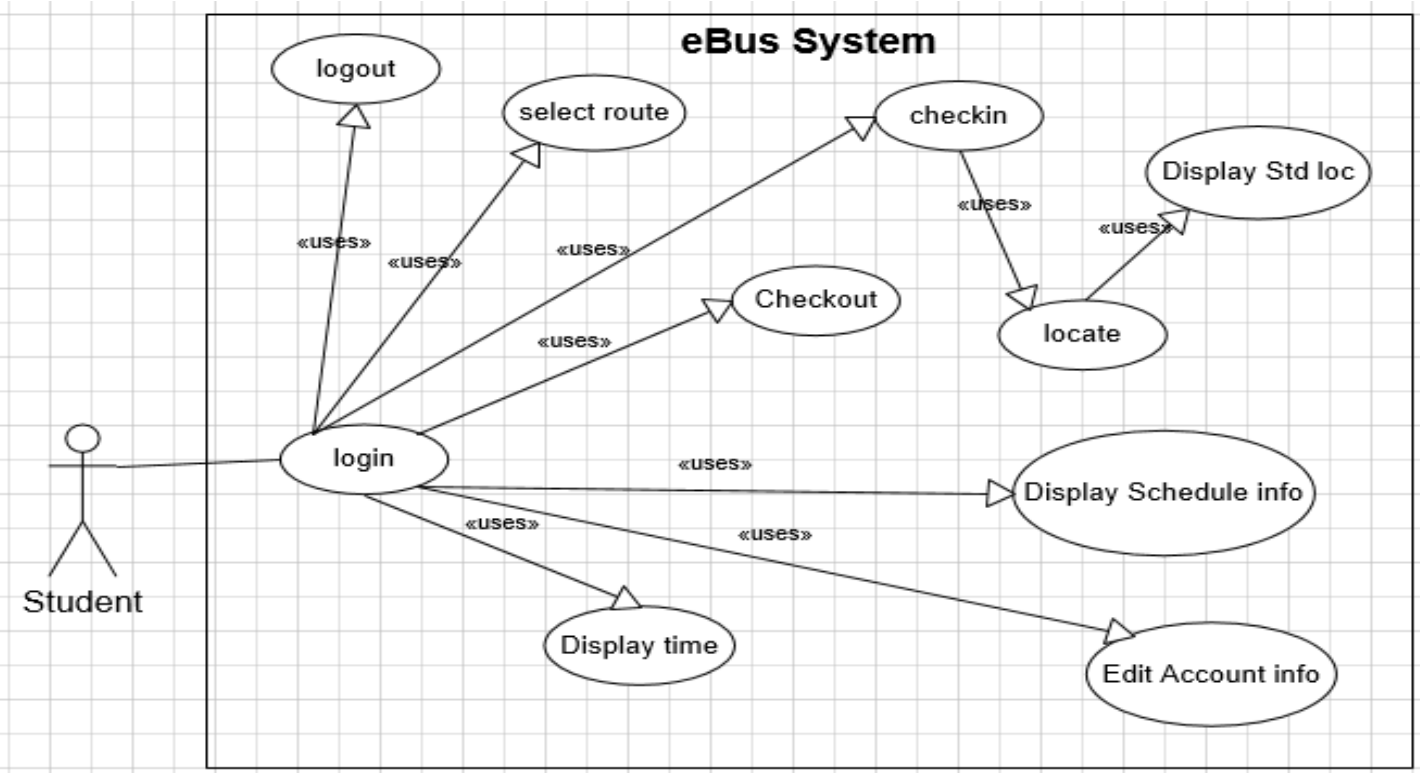

Figure 1 Student's use-case diagram

As shown in Figure 2 the system locates the bus location and appear it on the map, the driver can state the status of the bus as Out of Service or Full, and display schedule information.

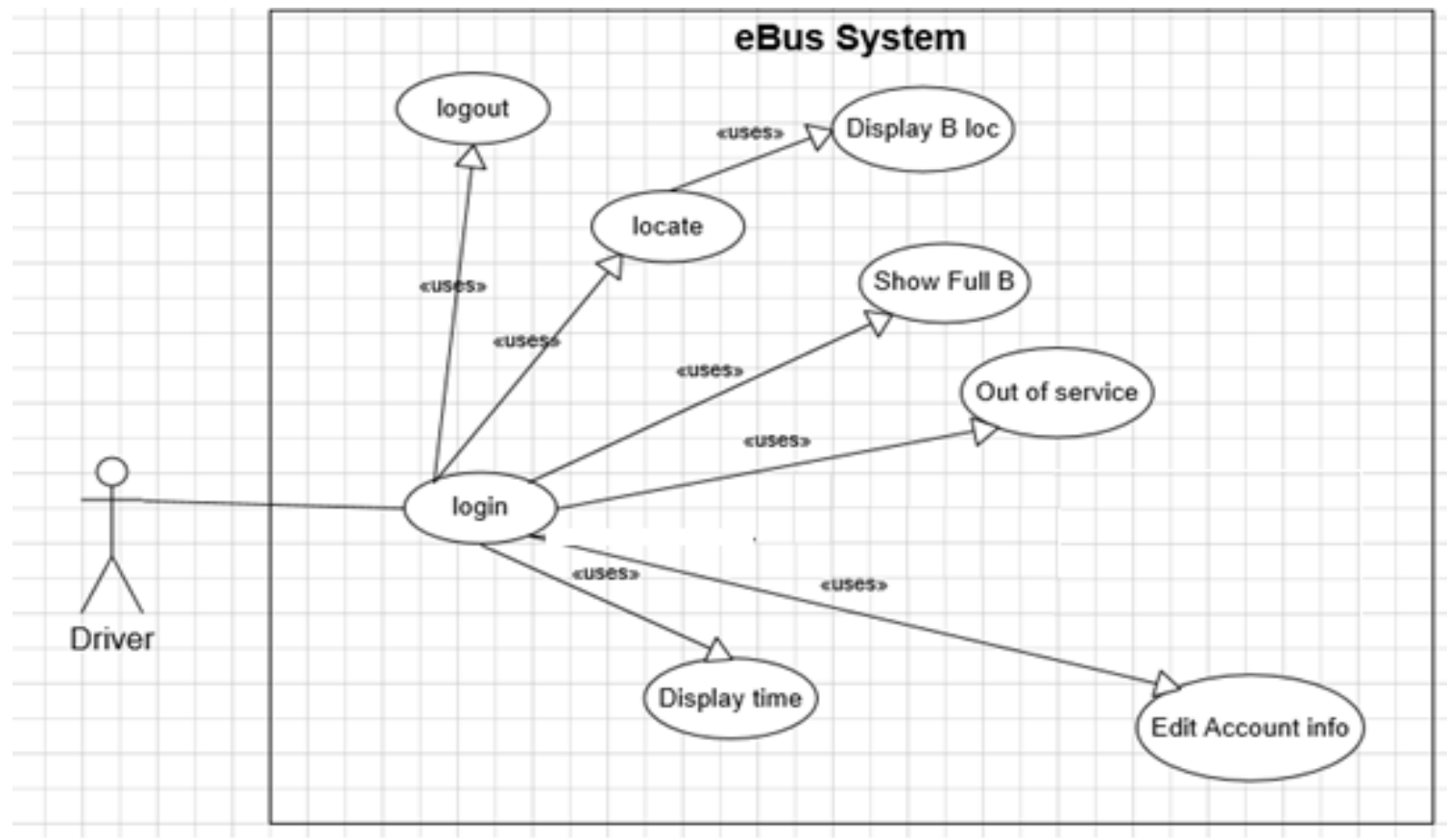

Figure 2 Driver's use-case diagram

Figure 3 shows the transportation manager use case diagram as he can login, view bus location and its status (full, out of service), edit information and logout. 
Mohammad Shkoukani et al.

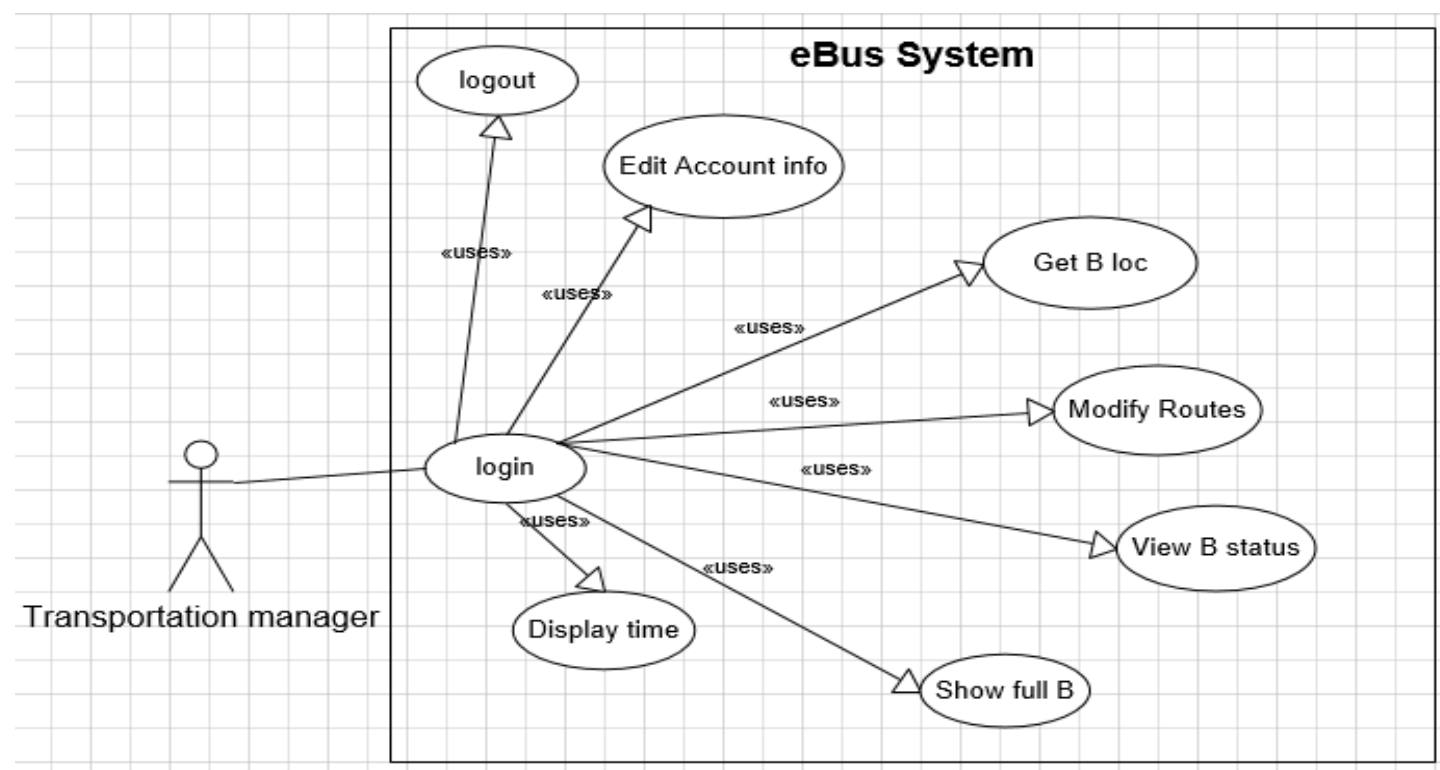

Figure 3 Transportation manger's use-case diagram

\subsection{System sequence diagram}

In this section we will describe two sequence diagrams that show how processes operate with one another. Figure 4 shows the interactions, messages between the student and the system. When the student login into the system, he can select a route, get the bus location, get schedule information, edit information, and finally logout.

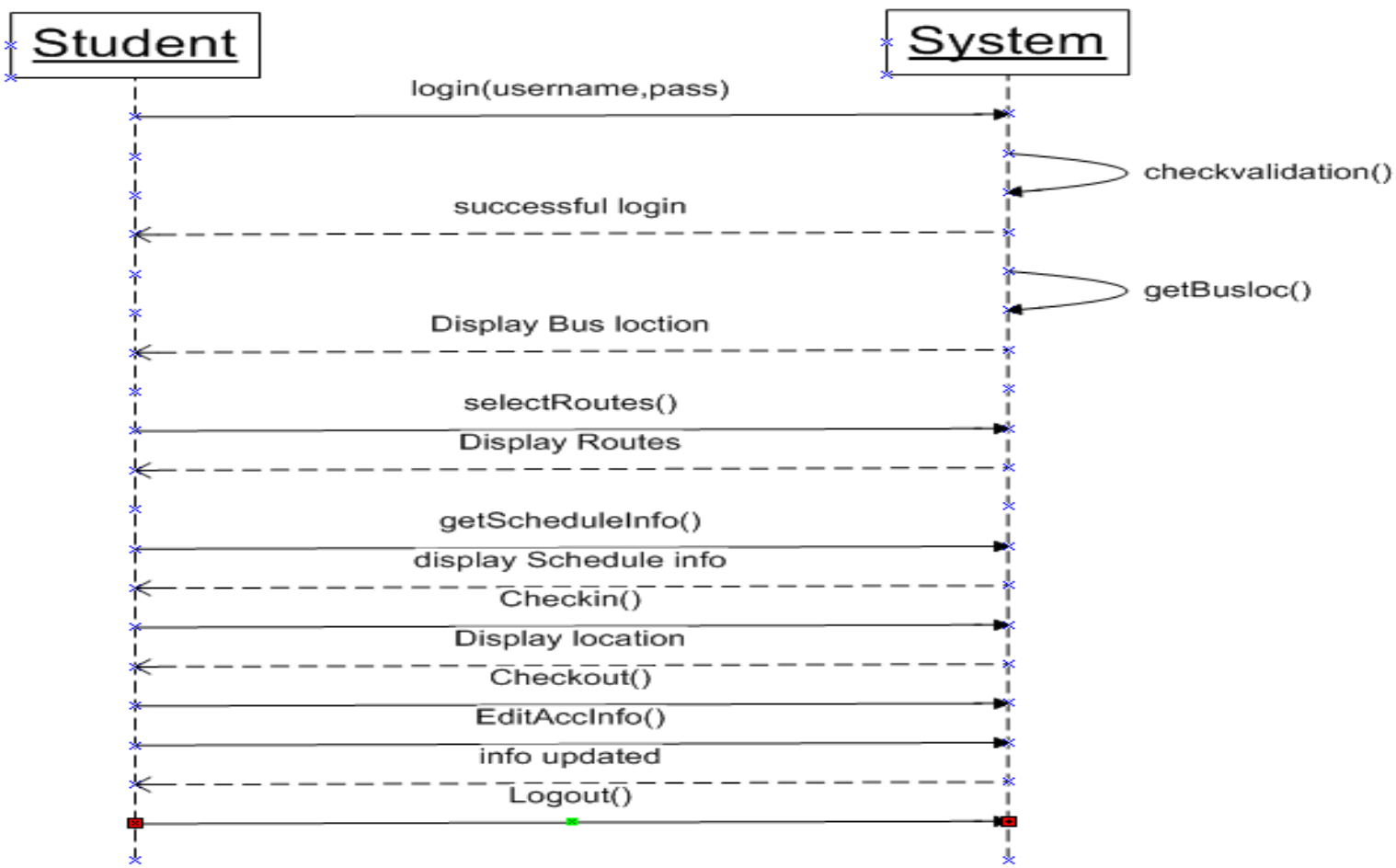

Figure 4 Student's sequence diagram

As shown in Figure 5 the driver and transportation manager interact with the system. The driver and the 12 transportation manager send their information (username, password) and the system validate them, 
they can edit their information, the bus drive can state the bus status as full or out of service and the system display the status to the transportation manager and finally logout.

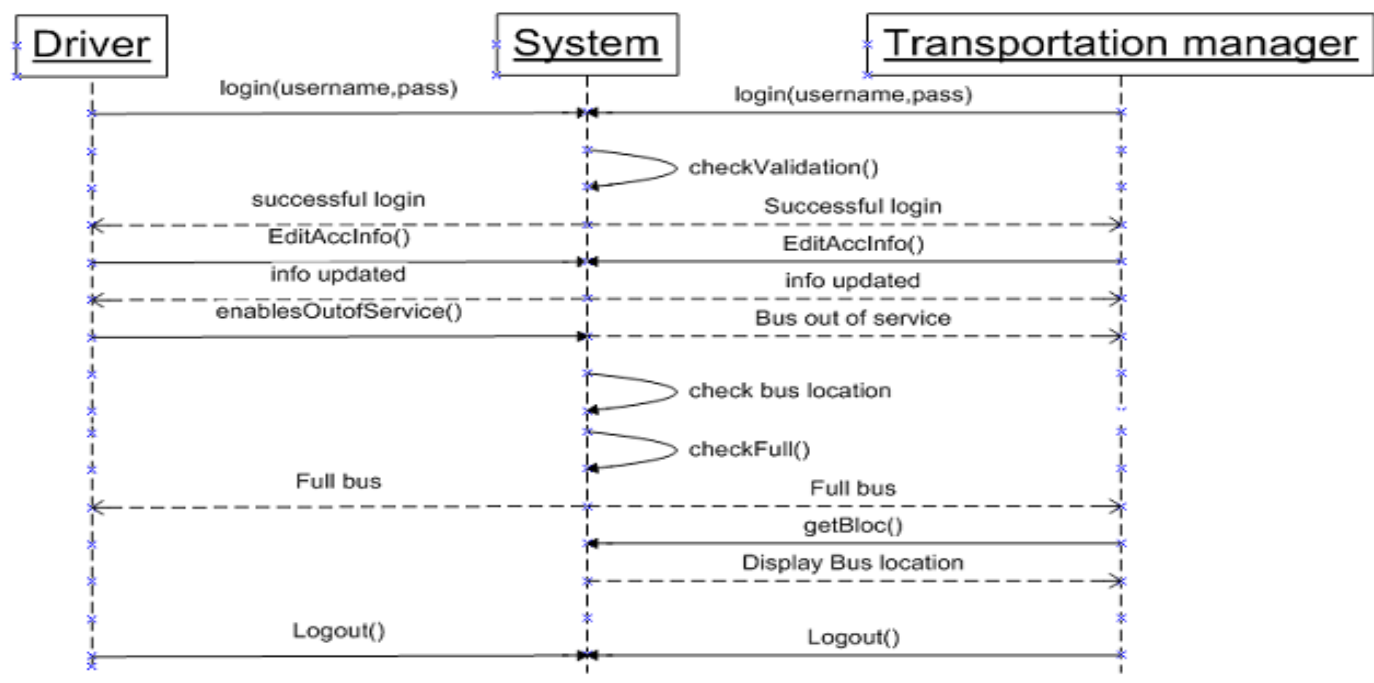

Figure 5 Driver and transportation manager sequence diagram

\section{System implementation}

In this section we will describe the main snapshots of our developed system. We will start with login page that is used by both driver and student to access the eBus system as shown in Figure 6.

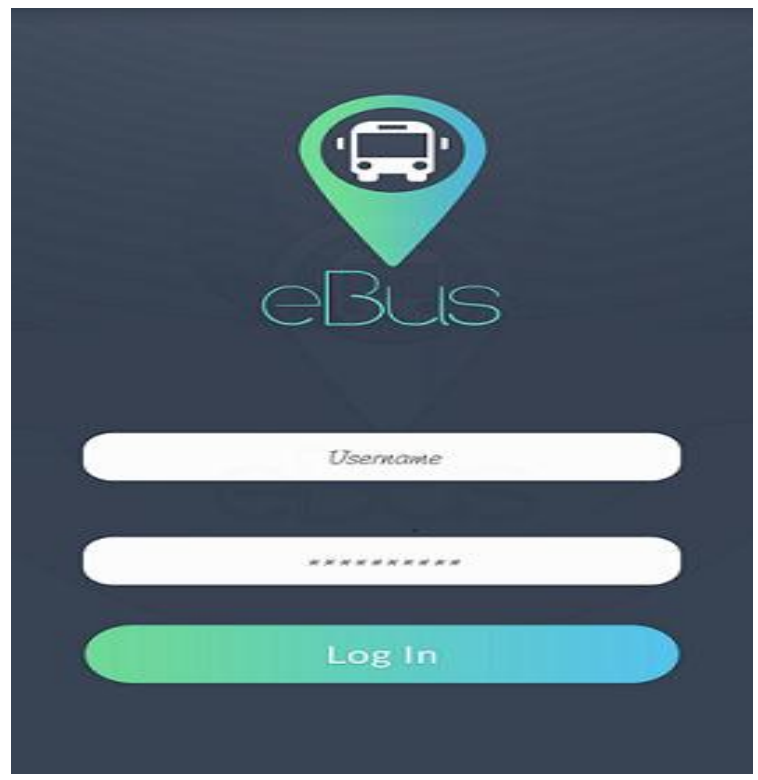

Figure 6 Driver and student login page

Figure 7 shows the student profile that represents the student ID, name, e-mail, phone and photo, the student can edit only his email and phone.

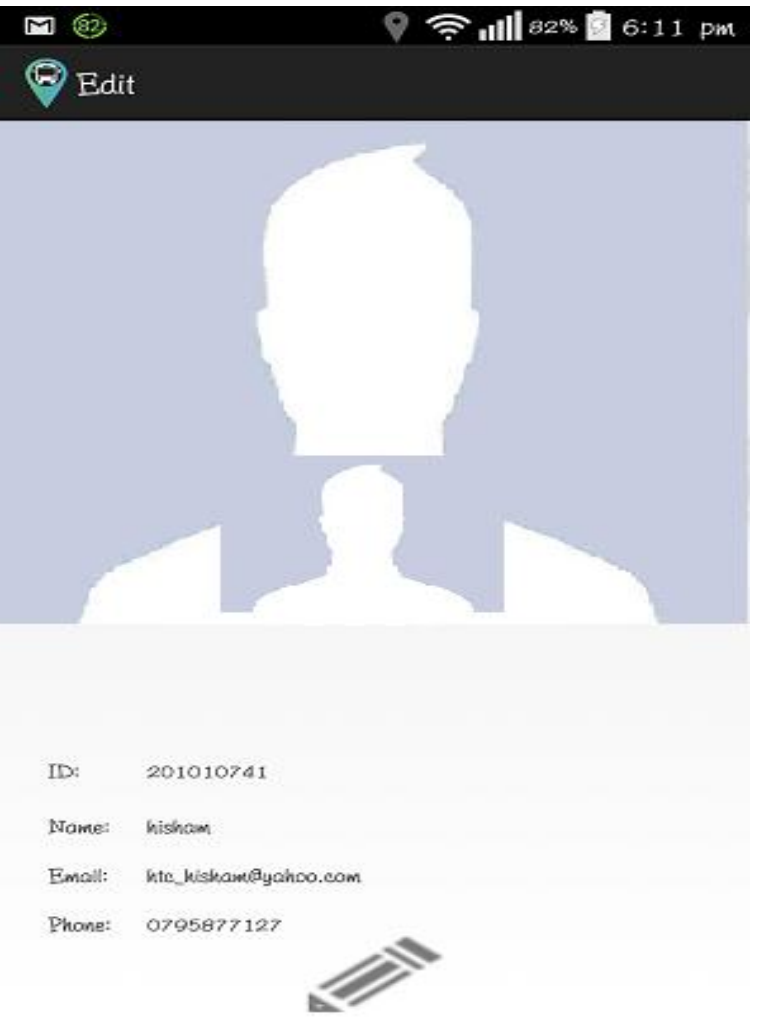

Figure 7 Student profile

Figure 8 displays the map when the student login into the system. 
Mohammad Shkoukani et al.

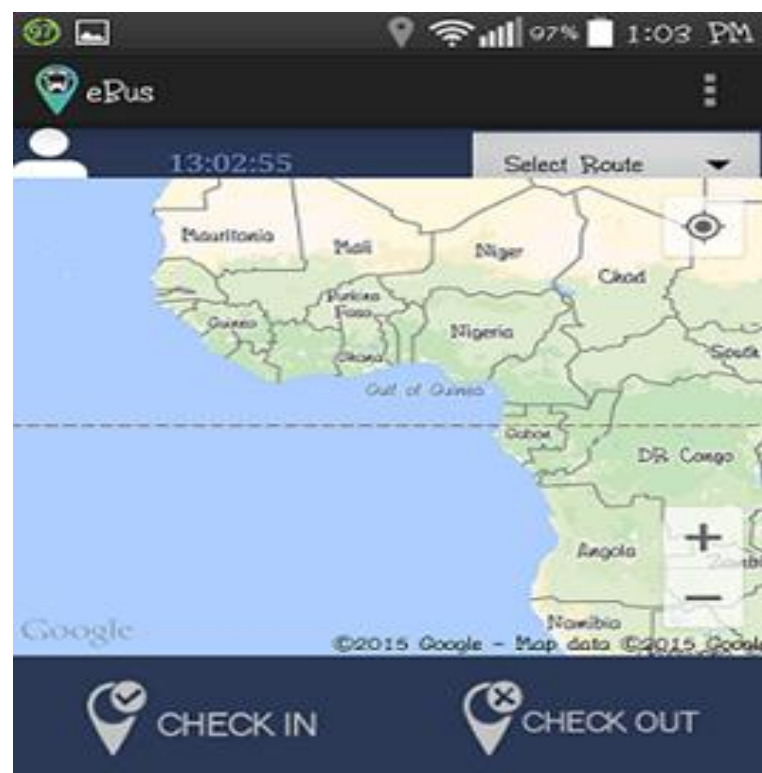

Figure 8 The map page

When the student selects the desired route from the map page, then the selected route, trip schedule, and student location are appeared on the map as shown in Figure 9.

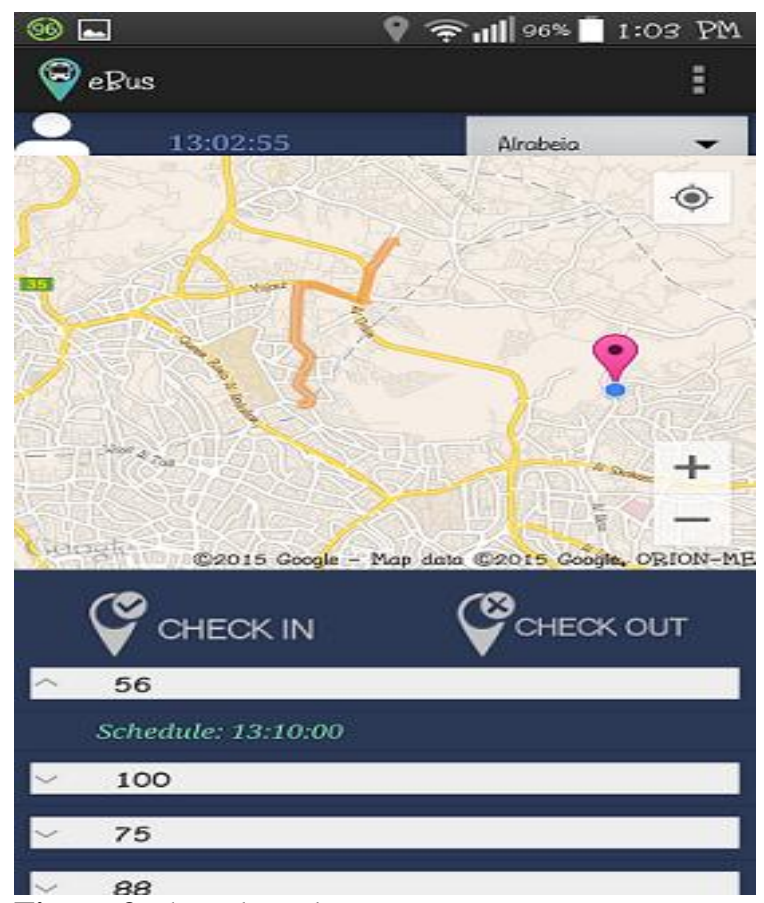

Figure 9 The selected route page

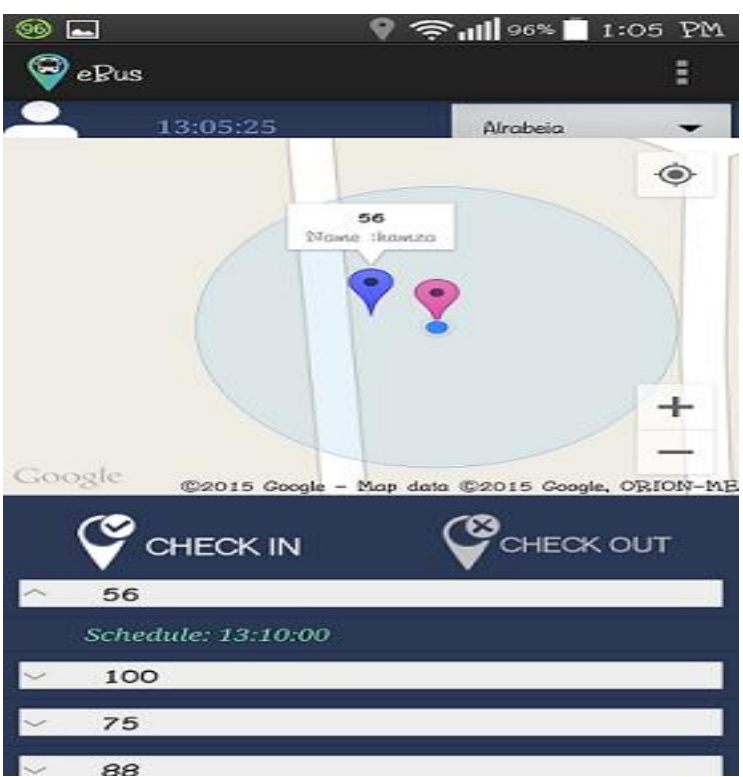

Figure 10 Selecting a bus and check in

Once the student selects the bus from the route page, then the selected bus color will become blue and its information such as bus number, drive name, and schedule arrival time will appear on the map, after that the student check in the bus as shown in Figure 10. If the bus is out of service for some reasons, then a message "Out of Service" will appear to the student as shown in Figure 11.

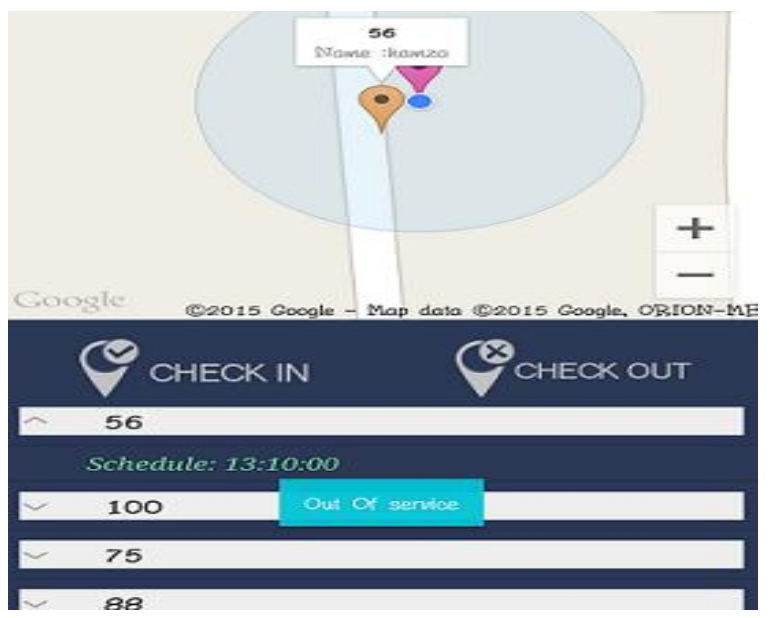

Figure 11 The bus is out of service

Figure 12 displays the map and the bus location when the driver login into the system. 


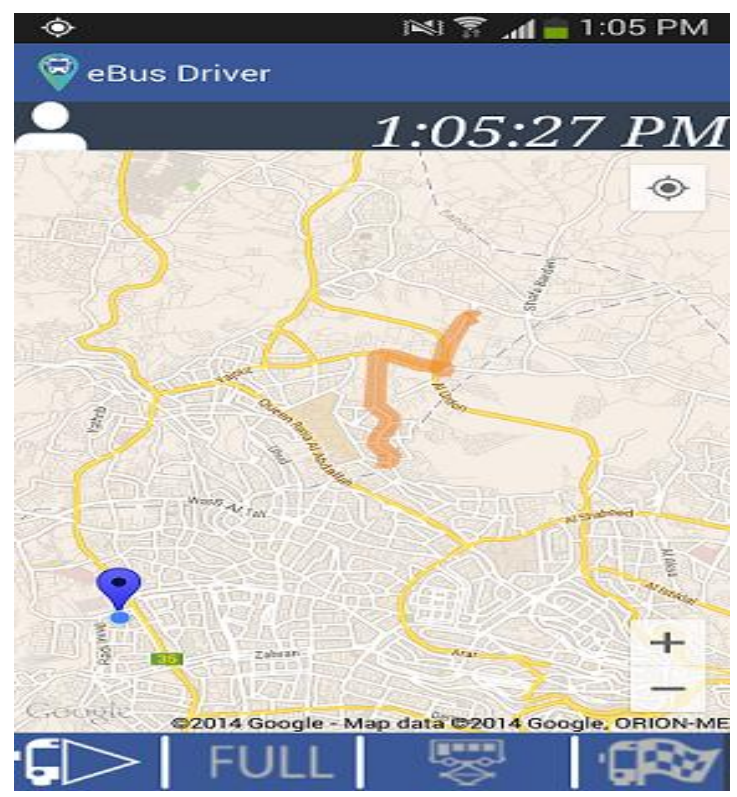

Figure 12 The map and bus location

Once the trip starts then the bus location and logged in student location will be displayed on the driver map as shown in Figure 13.

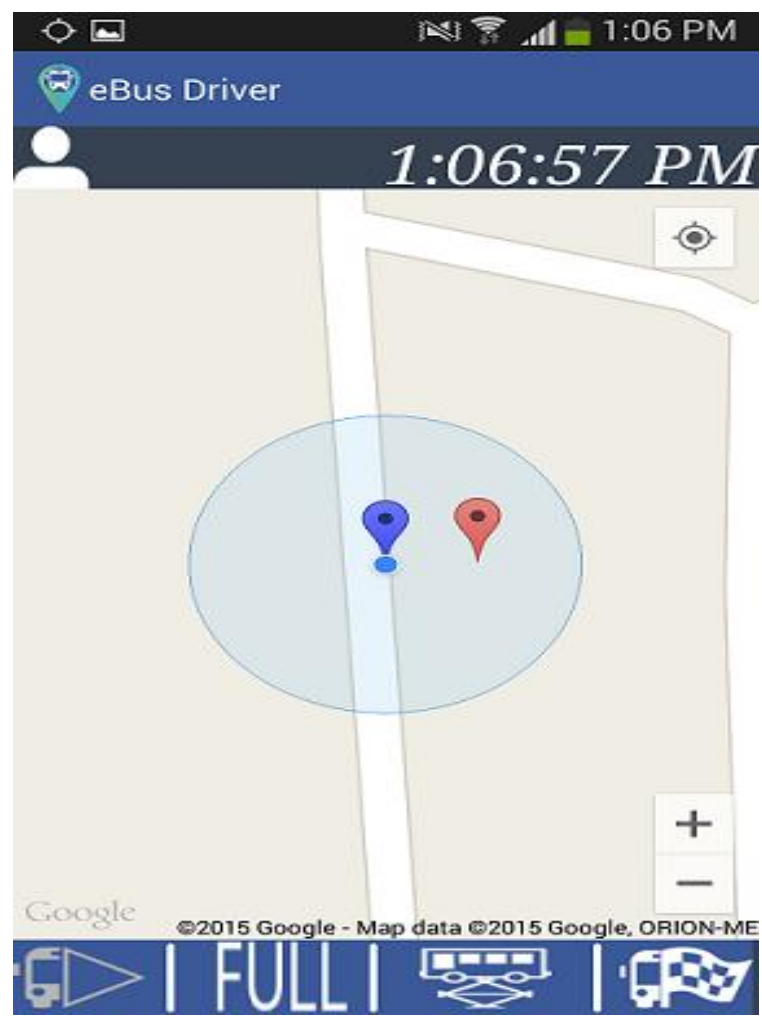

Figure 13 The logged in student location map

When the transportation manager logged in the system, then all available trips will appear to the 15 manager, including bus number, route name, and schedule time as shown in Figure 14.

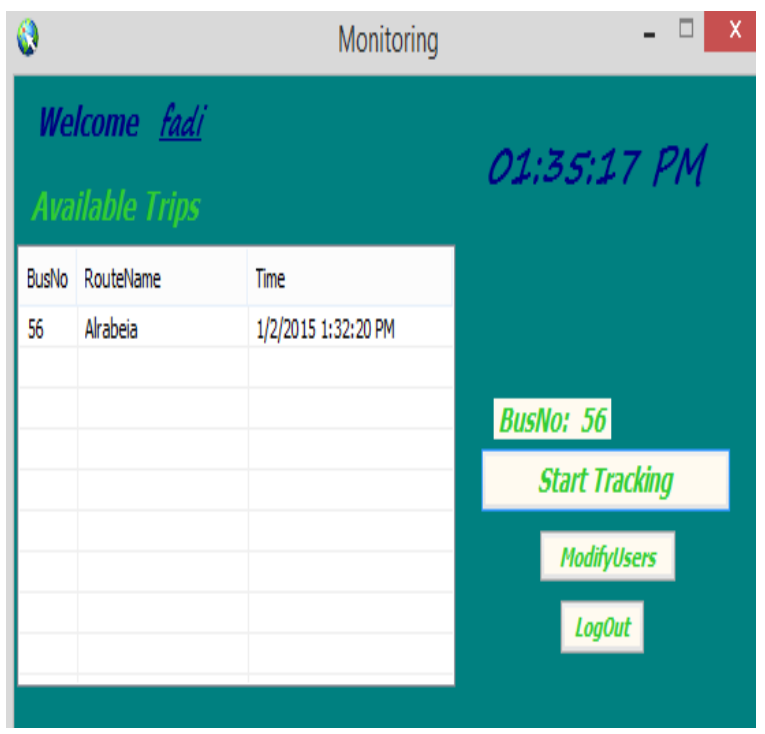

Figure 14 The available trips

Once the transportation manager chooses one of the buses for monitoring and controlling purposes then a list that contains buses' status (red color and windows notify balloon with voice indicates that the bus is full, if the color is orange then the status of the selected bus is out of service) as shown in Figure 15.

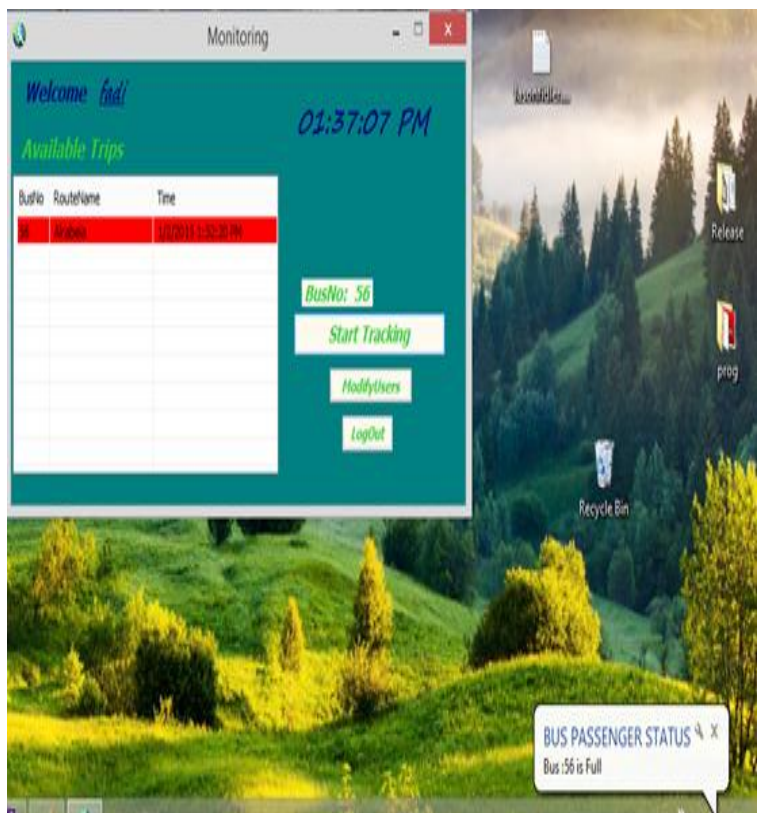

Figure 15 The monitoring and controlling page

Figure 16 shows the map for the transportation manager to track the chosen bus. 


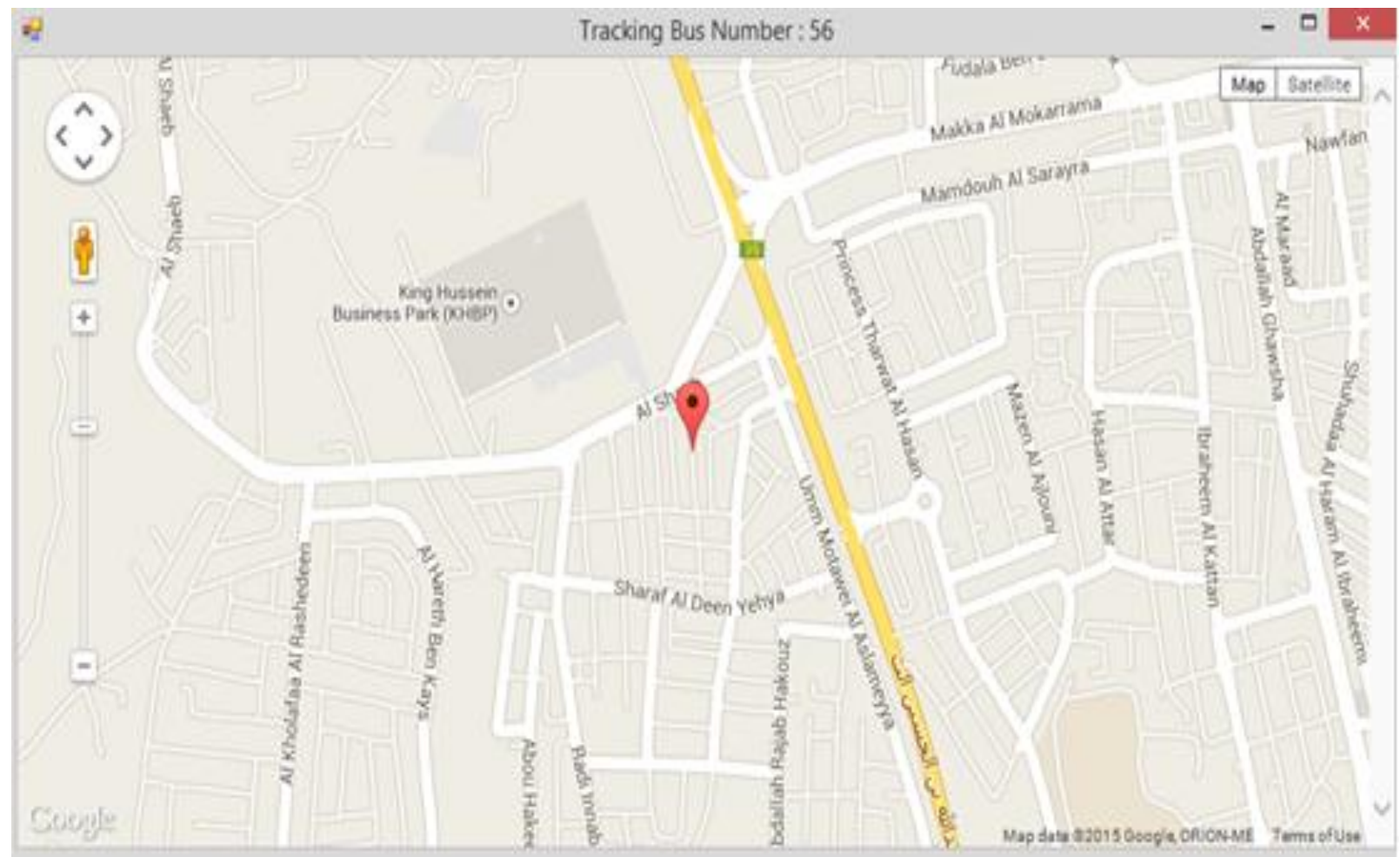

Figure 16 The bus tracking map

\section{Conclusion and future work}

The primary goal of our research is developing a transit system in order to facilitate the way of interactivity among the students, bus driver, and transportation manager, so through the eBus system that we have developed we provide a system with capabilities that enable the actors to monitor each other with some constraints that match Applied Science University transportation policy in such a way that is more efficient and effective by using new technologies. Finally, we believe that this system would play a major role in serving the society. In the future we hope to apply eBus system not just in our university but also in other universities and large organizations.

\section{Acknowledgment}

The authors are grateful to the Applied Science Private University, Amman, Jordan, for the full financial support granted to cover the publication fee of this research article.

\section{Conflicts of interest}

The authors have no conflicts of interest to declare.

\section{References}

[1] Schmöcker JD, Bell MGH, Lam WHK. Special issue: importance of public transport. Journal of Advanced Transportation.2004; 38(1): 1-4.

[2] Biagioni J, Gerlich T, Merrifield T, Eriksson J. Easytracker: automatic transit tracking, mapping, and arrival time prediction using smart phones. In proceedings of the 9th ACM conference on embedded networked sensor systems 2011(pp. 68-81). ACM.

[3] Biagioni J, Agresta A, Gerlich T, Eriksson J. Demo abstract: TransitGenie - a context-aware, real-time transit navigator. SenSys 2009 (pp. 329-34). ACM.

[4] Thiagarajan A, Biagioni J, Gerlich T, Eriksson J. Cooperative transit tracking using smart-phones. In proceedings of the 8th ACM conference on embedded networked sensor systems 2010 (pp. 85-98). ACM.

[5] GetTaxi application. http://gettaxi.co.uk/. Accessed 15 May 2015.

[6] Indiana University campus case study. http://www.iubus.indiana.edu/campus_bus/index.html. Accessed 10 June 2015.

[7] Parking and transportation services. http://www.utexas.edu/parking/transportation/ebus. Accessed 26 October 2015.

[8] Travel and Transportation. https://www.nyu.edu/life/travel-and-transportation/ university-transportation/routes-and-schedules.html. Accessed 26 October 2015. 


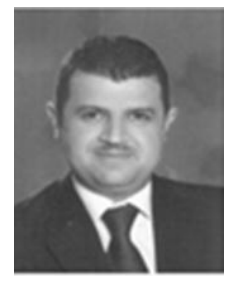

Mohammad Shkouknai is currently working as an associate professor in Applied Science University. He received his B.Sc. degree from Applied Science University, Amman, Jordan in 2002, M.Sc. and Ph.D. degrees from The Arab Academy for Banking and Financial Sciences, Amman, Jordan, in 2004, and 2009 respectively, all in Computer Information Systems. His research interests include Agent Oriented Software Engineering, System Analysis and Design, and Electronic Commerce Applications.

Email: m.shkokani@asu.edu.jo
Fadi Ajjam is currently a student in the faculty of Information Technology at the Applied Science University. His research interests include Computer Networking and Programming.

Hamza Ali is currently a student in the faculty of Information Technology at the Applied Science University. His research interests include Computer Networking.

Hisham Saleh is currently a student in the faculty of Information Technology at the Applied Science University. His research interests include Software Engineering. 